Hambrick, David Z., Altmann, Erik M., Oswald, Frederick L., Meinz, Elizabeth

J., Gobet, Fernand and Campitelli, Guillermo (2014) Accounting for expert

performance: the devil is in the details. Intelligence, 45. pp. 112-114.

\begin{abstract}
The deliberate practice view has generated a great deal of scientific and popular interest in expert performance. At the same time, the evidence indicates that deliberate practice, while undeniably important as a predictor of individual differences in performance, is not as important as Ericsson and colleagues have argued it is. In our main article, we found that individual differences in amount of deliberate practice accounted for about one-third of the reliable variance in music performance and chess performance, leaving the rest potentially explainable by other factors. Ericsson (2014-this issue) mounts a vigorous defense of his view, but the force of his defense is undercut by inconsistencies, oversights, and errors in his arguments. We reiterate that the task now for scientists interested in advancing understanding of expert performance is to develop and rigorously test falsifiable theories that take into account as many potentially relevant constructs as possible.
\end{abstract}




\section{Accounting for Expert Performance: The Devil Is In the Details}

We thank Anders Ericsson for his contribution to this special issue of Intelligence on acquiring expertise, and we credit him for generating a great deal of interest in expert performance. Ericsson, Krampe, and Tesch-Römer's (1993) study of musicians has been cited over four thousand times (Google Scholar) and was the stimulus for what the writer Malcolm Gladwell (2008) dubbed the "10,000 hour rule" (Ericsson, 2013). No psychologist has done more than Ericsson to promote the importance of environmental factors in acquiring expertise.

The goal of our study (Hambrick, Oswald, Altmann, Meinz, Gobet, \& Campitelli, 2014this issue) was to test Ericsson et al.'s (1993) claim that “individual differences in ultimate performance can largely be accounted for by differential amounts of past and current levels of practice" (p. 392, emphasis added). The claim was not supported: amount of deliberate practice accounted for about a third of the reliable variance in performance in music and chess, leaving the majority of the reliable variance unexplained. Thus, deliberate practice is important, just not as important as Ericsson et al. argued. Ericsson (2014-this issue) criticizes us for rejecting his view on a "common sense basis" (p. 18), but in fact, we reject his view on this empirical basis.

Ericsson (2014-this issue) mounts a vigorous defense of his view—but one we believe fails for four major reasons. First, Ericsson rejects evidence that challenges his view even though he has used the same type of evidence to support his view, which we argue is a double standard. Specifically, Ericsson criticizes us for ignoring "the effects of forgetting, injuries, and accidents, along with the differential effects of different types of practice at different ages and levels of expert performance" (p. 4). However, Ericsson et al. ignored these factors in their own published analyses, ultimately basing their conclusion about the great importance of deliberate practice on the relationship between skill in music and a single variable: self-reported amount of practice 
alone. Our reanalysis included studies that measured and operationally defined deliberate practice in the same way as in Ericsson et al. - indeed, our reanalysis included studies in which Ericsson was directly involved (Ericsson \& Lehmann, 1994; Tuffiash, 2002) and studies that he has explicitly praised for methodological rigor and repeatedly cited as support for his view (e.g., Charness, Tuffiash, Krampe, Reingold, \& Vasyukova, 2005). We followed the standards that Ericsson has set for himself in testing his view.

Second, Ericsson (2014-this issue) makes claims that are contradicted by claims he has made elsewhere. Most notably, Ericsson argues that although we criticize him "for attributing too much emphasis to the effects due to deliberate practice" (p. 2), he and his colleagues have always acknowledged that "there might be other types of individual differences than those linked to innate talent" (p. 2) - specifically, factors related to the proclivity and capacity to engage in deliberate practice (see Ericsson et al. p. 399). The implication here is that there may also be effects of these non-talent factors on performance-in other words, that they may have a direct link to performance, and thus may account for some of the variance in performance independent of deliberate practice. But elsewhere, Ericsson has claimed that the link of these factors to performance is indirect and mediated through deliberate practice. For example, he wrote, "The theoretical framework of expert performance explains individual differences in attained performance by the factors that influence the engagement in sustained extended deliberate practice, such as motivation..." (Ericsson, 2007, p. 4).

Third, Ericsson (2014-this issue) does not mention evidence that is inconsistent with his perspective. In particular, although Ericsson argues that there is no evidence that general cognitive abilities predict individual differences in domain-specific performance in highly skilled performers, he does not report critical findings of some of the studies he cites. For example, 
Ericsson notes that Meinz and Hambrick (2010) found a significant correlation between working memory and sight-reading performance, and argues that this finding is consistent with his perspective because the sample in that study included pianists from a low level of skill. However, Ericsson fails to note the central result of that study - that there was no interaction between deliberate practice and working memory capacity, indicating that working memory capacity positively predicted performance even at high levels of deliberate practice. Similarly, Ericsson notes that Horn and Masunaga (2006) found no correlation between Go ranking and scores on intelligence tests, but he fails to note that all other measures of Go-related performance in that study did correlate significantly with scores on intelligence tests (Masunaga \& Horn, 2001, Table 6). Describing the results of another study of sight-reading, Ericsson (2013) claimed that "Kopiez and Lee (2006) found that for musicians with lower sight-reading skill there was a correlation with their working memory. For musicians with a higher level of sight-reading skill there was no significant relation between their performance and their working memory" (p. 236). In this case, the error is one of commission: Kopiez and Lee reported no such finding.

Finally, Ericsson (2014-this issue) makes material errors in describing procedures and results of others' research (see Gagné, 2013, for further comment). He makes two such errors in describing a study of chess by two of us. First, he writes that "[d]ata was collected from 104 respondents, but Campitelli and Gobet's (2008) [sic] only analyzed 90 participants and did not describe the objective reasons for discarding 14 of the collected questionnaires" (p. 14). If this claim were true, then one would be well advised to dismiss the results of this study. However, this claim is not true. Campitelli and Gobet did not discard collected questionnaires; rather, as they explained in their article, there were missing data: "Not all players answered all questions, with the result that the number of data points varies across our measures" (p. 448). Second, he 
writes that "[i]t would be nice to have Gobet and Campitelli (2007) conduct a re-analysis that would identify the amount of practice required prior to first attaining the rating of master" (p. 13). If Gobet and Campitelli had not performed this analysis, then they would have had no solid basis for their conclusion that, contrary to Ericsson's view, there is a large amount of variability in the amount of deliberate practice people need to achieve a given level of skill in chess. However, as they report in a major section of their article, Gobet and Campitelli performed exactly this analysis and found that amount of deliberate practice required to first attain the rating of master ranged from 728 to 16,120 hours-leading them to conclude that "the slowest player spent 22 times more hours than the fastest player!” (p. 166).

Ericsson also calls into question our reporting of Gobet and Campitelli's (2007) results. He writes, "Surprisingly, Hambrick et al. (2014-this issue) reports the lowest value for a chess master as $832 \mathrm{~h}$ instead of the $728 \mathrm{~h}$ as reported by Gobet and Campitelli (2007, p. 166) without providing an explanation for the difference" (p. 14), and "Surprisingly, Hambrick et al. (2014this issue) reports the highest value for a chess master as $24,284 \mathrm{~h}$ instead of the $16,120 \mathrm{~h}$ reported by Gobet and Campitelli (2007, p. 166) without providing an explanation for the difference" (p. 14). The explanation is that the different numbers reflect different measures, which should be clear from the published reports of these studies, as the measures are clearly defined. The range of 832 to 24,284 hours reported in Hambrick et al. (2014) is for accumulated amount of deliberate practice. The range of 728 to 16,120 hours reported in Gobet and Campitelli (2007) is for hours to reach master status, as noted above.

Ericsson has made important contributions to research on expert performance. Nonetheless, his defense of the deliberate practice view is undermined by inconsistencies, oversights, and errors in his arguments. The fact remains that amount of deliberate practice does 
not largely account for individual differences in performance. The question now, for researchers interested in advancing the scientific understanding of expert performance, is what else matters. 


\section{References}

Campitelli, G., \& Gobet, F. (2008). The role of practice in chess: A longitudinal study. Learning and Individual Differences, 18, 446-458. doi: 10.1016/j.lindif.2007.11.006

Charness, N., Tuffiash, M., Krampe, R., Reingold, E., \& Vasyukova, E. (2005). The role of deliberate practice in chess expertise. Applied Cognitive Psychology, 19, 151-165. doi: 10.1002/acp. 1106

Ericsson, K. A. (2007). Deliberate practice and the modifiability of body and mind: toward science of the structure and acquisition of expert and elite performance. International Journal of Sports Psychology, 38, 4-34.

Ericsson, K. A. (2013a). Psychotherapy and the science of human excellence. Keynote presentation at the 2013 Psychotherapy Networker Symposium.

Ericsson, K. A. (2013b). My exploration of Gagné's "evidence” for innate talent: It is Gagne who is omitting troublesome information so as to present more convincing accusations. In S. B. Kaufman (Ed.), The complexity of greatness: Beyond talent or practice (pp. 223254). New York: Oxford University Press.

Ericsson, K. A. (2014). Why expert performance is special and cannot be extrapolated from studies of performance in the general population: A response to criticisms. Intelligence. doi: 10.1016/j.intell.2013.12.001

Ericsson, K. A., Krampe, R. Th., \& Tesch-Römer, C. (1993). The role of deliberate practice in the acquisition of expert performance. Psychological Review, 100, 363-406. doi: 10.1037/0033295X.100.3.363

Gagné, F. (2013). Yes, giftedness (aka "innate” talent) does exist! In S. B. Kaufman (Ed.), The 
complexity of greatness: Beyond talent or practice (pp. 191-221). New York: Oxford University Press.

Gobet, F., \& Campitelli, G. (2007). The role of domain-specific practice, handedness, and starting age in chess. Developmental Psychology, 43, 159-172. doi: 10.1037/0012 1649.43.1.159

Gladwell, M. (2008). Outliers: The story of success. New York: Little, Brown and Company.

Hambrick, D. Z., Oswald, F. L., Altmann, E. M., Meinz, E. J., Gobet, F., \& Campitelli, G. (2014). Deliberate practice: Is that all it takes to become an expert? Intelligence. doi: 10.1016/j.intell.2013.04.001

Horn, J., \& Masunaga, H. (2006). A merging theory of expertise and intelligence. In K. A. Ericsson, N. Charness, P. Feltovich, \& R. R. Hoffman (Eds.), Cambridge handbook of expertise and expert performance (pp. 587-611). Cambridge, UK: Cambridge University Press.

Masunaga, H., \& Horn, J. (2001). Expertise and age-related changes in components of intelligence. Psychology and Aging, 16, 293-31. doi: 10.1037/0882-7974.16.2.293

Meinz, E. J. \& Hambrick, D. Z. (2010). Deliberate practice is necessary but not sufficient to explain individual differences in piano sight-reading skill: The role of working memory capacity. Psychological Science, 21, 914-919. doi: 10.1177/0956797610373933 